Provided for non-commercial research and education use. Not for reproduction, distribution or commercial use.

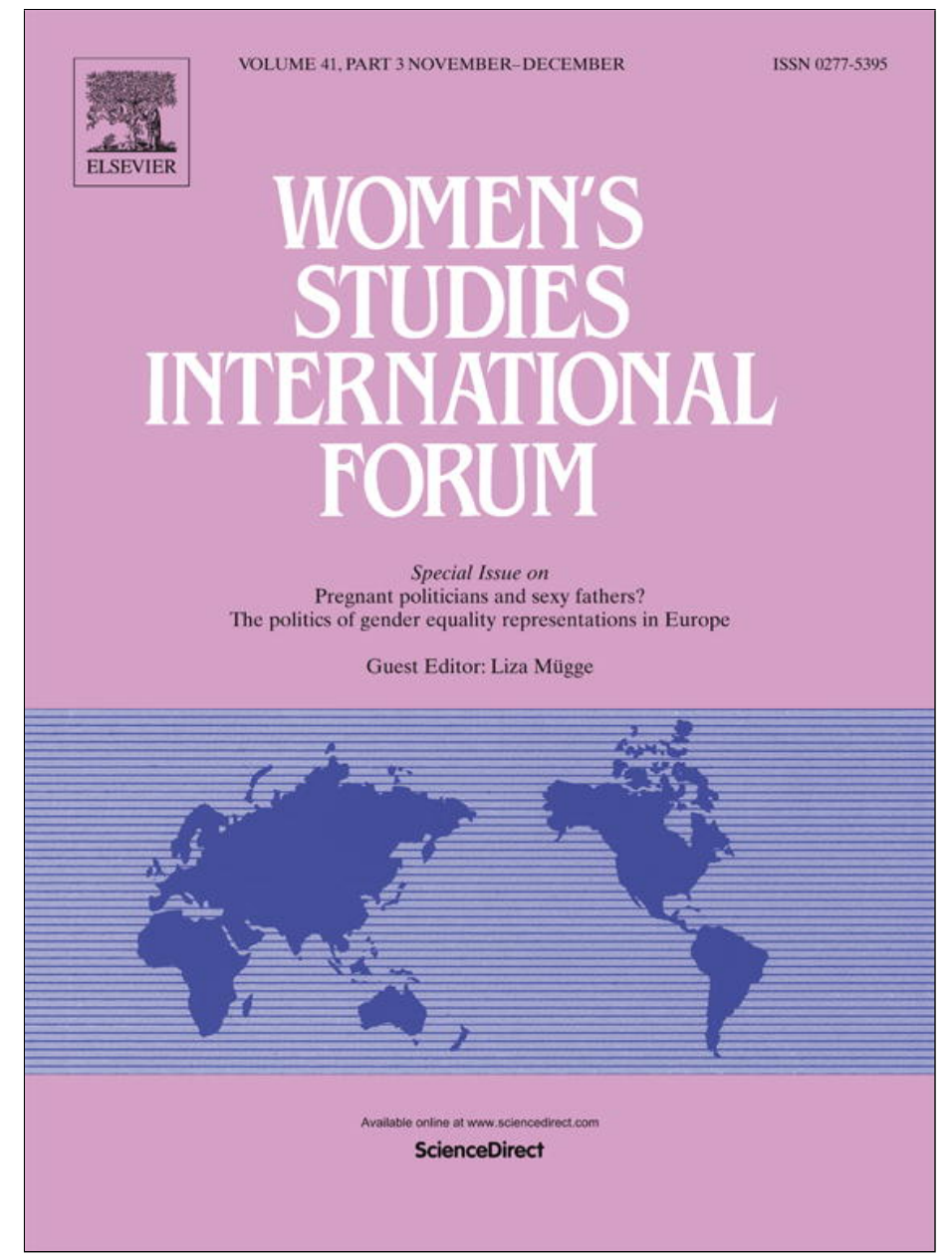

This article appeared in a journal published by Elsevier. The attached copy is furnished to the author for internal non-commercial research and education use, including for instruction at the authors institution and sharing with colleagues.

Other uses, including reproduction and distribution, or selling or licensing copies, or posting to personal, institutional or third party websites are prohibited.

In most cases authors are permitted to post their version of the article (e.g. in Word or Tex form) to their personal website or institutional repository. Authors requiring further information regarding Elsevier's archiving and manuscript policies are encouraged to visit:

http://www.elsevier.com/authorsrights 


\title{
Digital faiths: An analysis of the online practices of Muslim women in the Netherlands
}

\author{
Eva Midden*, Sandra Ponzanesi* \\ Utrecht University, The Netherlands
}

A R T I C L E I N F O

Available online 4 September 2013

\begin{abstract}
S Y N O P S I S
In response to current debates in Western Europe around Islam, gender equality and emancipation, this article aims to develop a new perspective on conceptualising 'emancipation' in feminist theory and practice. Our case study of how Muslim women in the Netherlands use digital media to negotiate their religious affiliations and multiple belongings shows that faith and religious practices are important markers of Muslim women's agency, both emancipatory and submissive. Theoretically, the article integrates classical feminist standpoint theory and situated knowledges with current debates on agency and subjectivity. Methodologically, our virtual ethnography draws on both online and offline data: postings on four websites for Muslims living in the Netherlands as well as focus group interviews with their editors/bloggers and women active in Dutch Muslim women's organisations. The data were analysed through Critical Discourse Analysis.
\end{abstract}

(c) 2013 Elsevier Ltd. All rights reserved.

\section{Introduction}

Many of the debates about Muslim women, emancipation and agency revolve around the role and interpretation of experience in feminist research (Midden, 2012). Questions that arise in popular media and academic debates include, for example, whether feminists can rely on 'universal' ideas about the 'emancipation' of women or whether they should engage more with women's experiences, even if these do not correspond to their ideas about emancipation. This is not a new discussion in feminism, where scholars have long engaged with the concepts of 'difference' and 'experiences'.

Sandra Harding and Donna Haraway have written extensively on issues of experience and knowledge production. Harding's standpoint theory is based on the originally Marxist idea that knowledge is socially situated and that one's position in society shapes and constrains what one knows, even what one can know. Standpoint theorists argue that knowledge from marginalised points of view can be more valuable than knowledge from a dominant position (Harding, 1991). Haraway later developed the concept of 'situated knowledges', arguing that we have to be accountable for the

\footnotetext{
* Corresponding authors at: Muntstraat 2a, 3512 EV Utrecht, The Netherlands.
}

way we see: where we see from and with which instruments (Haraway, 1991). In feminist research, this means that we have to position ourselves.

In addition to that, scholars such as Chandra Mohanty, Kimberly Crenshaw and bell hooks have written extensively on difference, arguing that gender alone is not enough to explain women's oppression, and that ethnicity, religion, sexuality and class need to be taken into account in any feminist analysis. One cannot simply focus on one axis of difference to understand oppression; we need to examine the intersections of the different axes involved.

This paper examines the relationship between religion and feminism by exploring the online activities and representations of Muslim women in the Netherlands. By approaching our findings through theories on experience and agency/subjectivity, we aim to develop a new perspective on 'emancipation' in feminist theory and practice and to engage with the experiences and opinions of women who at first sight seem to have a precarious relation to feminism.

The empirical data are based on research conducted for the European project MIG@NET, which focuses on transnational digital networks, migration and gender. ${ }^{1}$ Conducted in eight countries, the project addresses various sub-themes such as education, border crossings, communication flows, 
sexualities and social movements. Our research specifically deals with the religious practices of young Muslim women in the Netherlands and their online activities.

In the remainder of this article, we first discuss the context of the debates about feminism, religion and agency. We then outline our approach to studying the online activities of Muslim women and present our empirical findings. The paper ends by reflecting on how our findings can be used to rethink feminist conceptualisations of agency and emancipation.

\section{Feminism, difference and emancipation}

Feminism is anything but easy to define. Feminism has meant, and still means, different things to women in different times and places. Generally, we could say that feminists give characteristic meaning to 'sexual difference'. The different responses of feminists to sexual difference have often been divided into three categories: 'equality', 'difference' and 'deconstructionist' perspectives (Buikema and Smelik, 1993).

One could argue that the 'equality approach' dismisses differences between men and women (Chanter, 1998: 267$268)$. In the 1980 s, more and more feminists grew critical of it, arguing that women do differ from men and thus require different treatment. But this 'difference' approach not only includes differences between men and women, but also those between women - which remain particularly relevant when thinking about the relationships between religion, feminism and agency. Hence, if feminists want women to be equal, we have to consider the question: equal to whom? For it is not always clear what a society which puts an end to domination and androcentrism would look like Bock and James (1992). In this context, the term 'universal sisterhood' has become more and more problematic, because the apparent 'common identity' of women is generally based on the experiences of white, middle-class women (Ang, 2003: 191).

According to many women of colour, mainstream, universalist explanations of gender inequality are simply inadequate. Their lives and experiences are not only determined by their sex or skin colour, but also by the connections between them. The Combahee River Collective (1977: 232), for example, argued that different forms of oppression influence each other and that the synthesis of sexism, classism and racism is what creates the life circumstances of black women. Due to this, black feminists often did not feel 'at home' in traditional liberation movements; they needed to develop a politics that was "antiracist, unlike those of white women, and antisexist, unlike those of black and white men" (The Combahee River Collective, 1977: 233). See for example the article by Anna Korteweg in this issue for an analysis of honour related violence that explicitly includes the intersection between gender and 'race' and takes into account racism against specific groups and the existence of violence in these groups (Korteweg, this issue).

These notions about feminism and difference are still highly relevant: debates about Muslim women and gender relations in Islam, now raging in many Western societies, are forcing feminists to rethink how they can incorporate differences in women's struggles for equality. In the Netherlands, public debates about immigration and integration have increasingly become discussions about the role and position of Islam and Muslims in Dutch society. In this context women are usually depicted as victims of their culture and men as aggressors or oppressors (see also the article by Marleen van der Haar (van der Haar, 2013-this issue) for an analysis of the representation of migrant men in these discourses). Politicians and opinionmakers have often framed the presence of the Muslim community as a threat to liberal values in general and gender equality in particular. Some feminists have argued likewise. ${ }^{2}$

Religion, however, is central to the lives of many women, and some explicitly struggle for gender equality through their religion. Unfortunately this last group is underrepresented in most public debates, which mainly feature the voices of secular feminists ${ }^{3}$ and right-wing politicians defending versions of emancipation that focus on individualism and liberal freedoms. The fact that many religious feminists emphasize their right to choose a different lifestyle and an active relationship with God is often ignored or not taken seriously. This is where debates about Muslim women and emancipation diverge from earlier debates about feminism and difference. Regarding Muslim women, the disagreement not only concerns the basis of their oppression (e.g. the intersection of gender and ethnicity) but also the interpretation they give to their subjectivity and how they define emancipation itself.

We argue that it is important to nuance the association of feminism with liberalism and anti-religious critique. Rosi Braidotti, for example, has elaborately described the long history of feminists struggling for equality through religion or spirituality (Braidotti, 2008). She further argues that contemporary secular feminists who do not wish to be associated with Islamophobia have the responsibility to problematize secularism itself. Starting from Braidotti's critique, the current article aims to present a more nuanced perspective on the relationship between religion, secularism and feminism by focusing on how Muslim women in the Netherlands show agency in ways that are often not recognized as such. We believe that this will help feminists to re-conceptualize emancipation with more attention to diversity.

\section{From experience to agency and emancipation}

Standpoint theory and situated knowledges are important starting points for rethinking the relationships between religion, emancipation and feminism as they can help deconstruct dichotomous way of thinking. For example, one could argue that religious women cannot simply be considered oppressed because they also fight for equality, albeit in other ways. Alternatively, one could argue that some women may not want the equality or freedom that liberal feminists stand for (see also Bracke, 2008). Standpoint theory speaks to the first argument: there are different ways to emancipate and those who experience oppression can develop knowledge from their own standpoint on how to challenge it. Situated knowledges speak to the second: it shows us that knowledge always comes from a particular perspective, which we need to be accountable for. We see, for example, that interpreting agency as resistance is not neutral or universal and derives from particular assumptions.

We argue that applying these ideas on standpoint and situated knowledges to debates about agency and subjectivity for example in the recent works of Saba Mahmood and Rosi Braidotti - enables us to rethink the concept of emancipation in feminist theory and practice. We believe that Mahmood and Braidotti add two important arguments to this debate.

First, Mahmood argues that feminists have to separate their analytical and prescriptive work, especially regarding 
theories of agency (Mahmood, 2005). Most feminist thinking is primarily liberatory, where agency is described as a model of subordination and subversion. Mahmood argues that this attachment of agency to progressive politics is problematic: if there are different ways to change the world depending on social, political and historical context, the meaning of agency should not be fixed in advance. If we really wish to understand the lives, experiences and strategies of all women, we shouldn't reduce their activities and ways of being to, simply, subversion and subordination.

Second, Braidotti proposes that subjectivity can be described in a 'political' way without being negative or fixed. Subjectivity is not about producing radical counter-subjectivities, but about daily practices and negotiations within dominant norms:

"Political subjectivity or agency therefore consists of multiple micro-political practices of daily activism or interventions in and on the world we inhabit for ourselves and our future generations" (Braidotti, 2008: 16).

In what follows, we apply this postsecular framework of thinking about agency and subjectivity to the results of our MIG@NET research.

\section{Approach to the empirical research}

Our research within MIG@NET focuses on the participation of immigrant women in religious digital networks and the ways in which such participation structures their religious practices and emancipation. Through interdisciplinary and intersectional research, we aim to add to our understanding of the digital activities of Muslim women in the Netherlands, their participation in transnational (and religious) networks, and the role of various categories of difference (such as age and nationality). After a preliminary analysis of the 4 websites we researched, we decided to focus on four prominent concepts/ themes: agency (and emancipation), secularism, generations, and the public sphere (and visibility). This article focuses on the first theme, that of agency. Our methodology combines Critical Discourse Analysis (based on the work of Norman Fairclough) and online and offline ethnography (based on the work of, among others, Christine Hine).

To collect data, we relied on the methods of virtual ethnography or netnography. Data collection through netnography entails communicating with people from an online community in many different ways (Kozinets, 2010). Participating in the community is essential, as is collecting data in a manner that takes into account the context of the community. It means trying to find a balance between the role of the reflexive, autobiographical and subjective cultural participant and the systematic, somewhat objectifying scientist (Kozinets, 2010). Our methods provided us with a rich set of data, including archival data (directly copied from the websites), elicited data (created by researchers through interaction with community members) and fieldnotes (researchers' observations during the investigation).

For offline data collection, we mainly relied on focus groups. The interaction and multivocal narratives they foster make focus groups suitable for accessing marginalised or 'subjugated' voices (Leavy, 2007). Focus groups are generally considered to create the most equal relationships possible between researchers and interviewees (Wilkinson, 2004). In contrast to the one-on-one interview, the researcher in a focus group is outnumbered by the interviewees. This can make it easier for the latter to take control of the conversation and shift the balance of power. Another advantage of focus groups for a research project like this one is that they produce socially situated knowledges. The dynamics in the group can make it possible for participants to make connections between certain opinions that they had not been able to make before. If, for example, one woman mentions an experience, another may remember that she has been through something similar. This is important because it can help participants recall things they had forgotten about or would otherwise consider unimportant; it also shows how individual experiences can be turned into ‘collective sense making' (Wilkinson, 2004).

Critical Discourse Analysis was used for the analysis of online data. Generally, we can call a combination of texts and images 'a discourse'. Here we use Norman Fairclough's definition in Language and Power: "language as social practice determined by social structures" (Fairclough, 2001: 14). An important point to note is that discourses both have effects on, and are determined by, social structures (Fairclough, 2001).

We use Fairclough's work on CDA because power and power relations are central to his work; while his background is in linguistics, his approach to discourse is also useful for social scientists and philosophers. Fairclough distinguishes between two different forms of power related to discourse: power in discourse and power behind discourse (Fairclough, 2001). The first refers to the fact that powerful participants in discourse can control and constrain less powerful participants. Power behind discourse refers to the social order of discourse, including things such as access. Both aspects of discourse have changed with the rise of digital media. The websites we analysed are good examples of how access to media has increased immensely for minorities, allowing them to present and discuss news, experiences and issues related to their own communities on their own terms. This also provides them with the opportunity to change how certain topics such as gender equality are discussed. This paper is an example of this.

The sample for our case study consists of four Dutch websites where Muslim women discuss various aspects of their lives in connection to their religious affiliation: wijblijvenhier.nl (We are Staying Here), moslimagids.nl (Muslim Women's Guide), turksestudent.nl (Turkish Student) and nieuwemoskee.nl (New Mosque). We selected both websites for women and men (such as wijblijvenhier.nl) and websites that aim to be only for women (such as moslimagids.nl) and included website posts, blogs, stories, question-and-answer sections, and forums in our analysis. In choosing the websites, we aimed for a sample as diverse - in ethnicity, religious strands, political aims, age, migration status, level of education, etc. - as the Muslim women living in the Netherlands.

We also held focus-group interviews with website initiators and/or editors, women active in Muslim women's organisations, and individual women reached through snowballing. We selected respondents of various ages, educational backgrounds, and from different (among others, Turkish, Moroccan and Afghan) ethnic groups as well as Dutch converts to Islam. Our aim was to represent the broadest possible segment of Muslim women active online in the Netherlands. In total, we held six focus groups with women from the Muslim women's organisation Al Nisa, the Islamic Student Union of Amsterdam, the 
Turkish Muslim women's organisation ISRA, bloggers of the website 'Wij blijven hier', editors of the website wijblijvenhier.nl, and a non-organised group of Afghan women living and studying in Amsterdam.

\section{Muslim women, religious practices and online activities}

In the interviews conducted for the MIG@NET research, respondents talked extensively about how they use the Internet in their organisations and what role it plays in their religious practices. They often began by relating their experiences on (Dutch Muslim) Internet fora and how they use the Internet to gather information about their faith.

Most respondents considered being a Muslim as something that affects all aspects of life, including their online activities:

"It reaches through your whole life. Religion is not what you do aside from your life, it is not just a part of your identity, but also the way you think and plan. Education is for example part of religion and what you believe in. Islam is very broad and has certain rules for everything. If you stay true to those rules, it then affects the way you look at the world, how you make considerations and even how you dress. In short, Islam is my life." (ISA interview, 2012, our translation)

Especially for the younger interviewees, the Internet played an important role in their daily religious practices, for example searching for Dua's (prayers), sharing experiences (by watching videos of other Muslim women), or reading Islamic stories. One interviewee mentioned that she looks up prayers that help her to feel better on Youtube:

"When I am in a rough period then I listen to Dua's on the Internet and sometimes forward them. If you really believe in them and are brought up with them, it can calm you down... I also put them on Facebook, and I do not care what people think about it. I often get 'likes' and positive reactions, also from people who do not believe or have a different faith." (Afghan students interview, 2012, our translation)

There is a difference between (inter) active and passive use of the Internet when it comes to religious practices. Whereas forum discussions are places where people actively discuss truth claims or ask questions about daily religious practices, other websites function more as sources of information and leave interpretation to readers. Some people feel the need to discuss their religion and religious practices as mainstream newspapers in their view often do not know how to discuss religion. Islamic forums are considered a good alternative. Others prefer to interpret and read religious sources themselves.

\section{Online activities, religious practices and agency}

\section{Redefining emancipation and multiple critique}

Our initial analysis of the online representations of Muslim women in the Netherlands revealed at least four forms of subjectivity or agency that are, in one way or another, related to the emancipation of women and gender relations in
Islam: 'rethinking emancipation', 'multiple critique', 'fighting sexualisation' and 'living according to strict rules' (see also Midden, in press).

First of all, many Muslim women present and discuss alternative interpretations of emancipation. Ceylan Pektas Weber argues on the website 'New Mosque' that numerous female Muslim intellectuals have shown that attention to women in the holy texts is an important aspect of the struggle for equality and justice:

"Men and women are depicted as equal in the Qur'an (...). The traditional interpretations, mainly produced from a male perspective, do not do justice to this starting point."

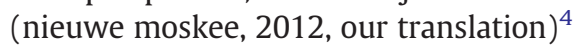

Whereas secular feminists often find it unacceptable for women to put a higher force above them, these Muslim women show that it actually gives them authority. Discussions on gender relations in the Qur'an can thus not only transform Islam, but also feminist struggles. The above author shows that it is eminently possible to fight for equality through religion and to rethink emancipation with the help of holy texts.

Such arguments on knowledge and the position of women were also evident in our interviews:

"The prophet, peace be with him, has made sure that women have gained more rights (women obtained the right to divorce. They were seen as equal to men, and to obtain knowledge, and to work). My most important example was the prophet, peace be with him, and how he interacted with his women. How his women had so much freedom. And that is, for me, emancipation, and Islam." (Wijblijvenhier interview, 2012, our translation)

The life of the Prophet and his wives was often an inspiration for women to be ambitious in life, strengthening their belief that women and men are equal in Islam:

"Sometimes, some people say that religion is restrictive for emancipation. And then you hear someone, a female Imam, who talks about the wife of Prophet Muhammad, who occupied herself with public administration. And that is actually really interesting, and then you think; hey!

I can do that too!" (ISRA interview, 2012, our translation)

Despite these women's interest in emancipation, feminism often did not appeal to them; some were in fact highly critical of feminism. The blogger Akachar, for example, found it problematic that women who fight for equality tend to adapt too much to the dominant group; feminists, she argues, would be better off re-valuing femininity to improve the position of women in society, without falling into the trap of trying to become the same as men. ${ }^{5}$

These example show that where some Western secular feminists have often described emancipation as an individual process towards independence, these Muslim women bring forward alternatives perspectives on the concept of emancipation. If one connects these examples to the theoretical framework of the above, it becomes visible that this can be related to the subjectivity that Rosi Braidotti describes and that different standpoints can be a starting point for developing new feminist knowledges. The passages quoted above also reveal the importance of considering the intersections of gender, ethnicity and religion. Rather than focusing on gender 
equality from only one axis of difference, more nuanced perspectives can be developed by examining how gender intersects with, for example, religion, nationality and class.

A second form of agency we encountered online is related to Miriam Cooke's concept of 'multiple critique' (2002). Cooke argues that Muslim women who aim for gender equality within Islam inhabit complicated and sometimes contradictory locations; in response to often negative representations in, for example, popular western media, they have developed 'multiple critiques' (Cooke, 2002). This means that they discuss gender roles in their local and religious communities, challenging conventional interpretations of holy texts and traditions, while defending their religious and national communities from outside disparagement. The idea of multiple critique is especially relevant for online posts by Muslim women as their possible audiences are very broad and open, meaning they have to constantly negotiate their multiple positions.

We see this balancing act between different discourses as a form of agency, one that is evident in, for example, forum discussions on headscarves. In one discussion on its possible ban, almost all participants stated that they will keep their headscarf on no matter what. Here the headscarf becomes a tool (of agency) to make a statement against (Western) secular society. Ceylan Pektas Weber below reflects on the headscarf and the respect people (can) give to each other as human beings; she argues that the headscarf has been criticised, cursed and considered as oppressive and backwards, while there is also a movement describing it as emancipatory, a sign of assertiveness or an expression of one's identity. ${ }^{6}$

"In both cases, I experience a growing problem and feeling of narrowness. Not in the least because of the often used word 'symbol' when talking about the headscarf. A symbol represents something, an ideal, a thought, a movement. But usually not a person. And in both responses to the headscarf, the women wearing one run the risk of becoming the representative of such an ideal, vision, or movement, and not a person. Women who wear headscarves have more and more become the headscarf. A thing, not a person." (nieuwemoskee, 2012, our translation) ${ }^{7}$

On the website turksestudent.nl, we also see participants referring to Dutch culture in order to criticise the prevailing negativity about headscarves and veiling. The poster below states: "Why do you wear a headscarf?" - "Why do you not wear one?" It clearly aims to shift the constant questioning of Muslim women regarding their choices to those women who make the more accepted choice of not wearing a headscarf.

The interesting aspect of multiple critiques is that it shows that many women are critical about their own communities (e.g. by fighting for more possibilities to be active in the public sphere or by redefining the holy texts and the role of women in them) and at the same time might not want to fight against (all) gendered religious traditions. In other words, they combine different forms of agency and show that they have developed critical standpoints about their communities.

\section{Going against sexualisation and living according to strict rules}

A third way of rethinking gender relations we observed online is the critique of Dutch or Western values regarding sexuality and consumerism. According to the blogger Smahane, a better society can only be achieved if we manage to do something about sexuality and the role of feminism in it. $^{8}$ Whereas previous posts mainly differed in their interpretations of emancipation, women's rights or feminism, Smahane here criticises feminism for its aims, in this case free sexuality for women. While one could dismiss this as a form of false consciousness, this (by excluding arguments that do not suit specific Western ideas about equality) would be the easy way out and neglect well-made points made by women. We instead argue that such positions are clear expressions of agency and important starting points for the development of alternative feminist knowledges.

Following Haraway, we argue that if feminists want to prevent the 'god trick', they have to acknowledge that all visions are partial and mediated (Haraway, 1991: 190). Seeing is about translating; if we want to recognise tensions, contradictions, transformations and resistances, we need to be aware that we only command partial views from certain locations (Haraway, 1991: 195). According to Haraway, standpoint alone is not enough to produce embodied and objective knowledge; we need instruments to actually see something from a certain standpoint. The most important instrument for a researcher is 'critical positioning': not identity, but critical positioning, produces partial, locatable and critical knowledges (Haraway, 1991: 193).

Writer Daphne Meijer of the website 'New Mosque' provides an interesting example of the above point. She argues that feminism and faith can be combined in the struggle against sexualisation and refers to a case in Israel where a young girl was yelled at and spit on by ultra-orthodox men:

"When Ultra-Orthodox men say that they find women in shorts or tight clothes offensive, and that pictures of halfnaked models in bus stops, etc. raise their aversion, they are actually saying that they are confused by the erotic challenge." (wijblijvenhier, 2012, our translation $)^{9}$

The question, Meijer argues, is "who is responsible and how do we solve this"? One could either blame the women or the men, but she believes both modern orthodox Judaism and modern feminism can do better: "men should indeed learn to not glance to every female, but the public sphere would be a much nicer and safer place, when the open sexualisation decreases". ${ }^{10}$ This shows that one can combine feminist and religious arguments, and that there exist affirmative alternatives beyond the stark binary of anti-women religious perspectives and (neo-) liberal emancipation.

The fourth way of rethinking agency observed in our research for MIG@Net was the practice of obedience to strict rules. Previous examples all revealed different interpretations of emancipation and female agency in Braidotti's sense: as daily negotiations and (affirmative) alternative perspectives on emancipation. But not all women in our research desired emancipation as such. Especially on the website 'Muslim Women's Guide', women were mainly talking about what they were allowed and not allowed to do according to the Qur'an and how to live accordingly in the Netherlands.

Although the practice of living according to strict rules is generally not associated with agency, one can read agency especially as suggested by Mahmood - in the embrace of 
modesty or in the critique of Western ideas of freedom. Though these perspectives challenge secular feminist's ideas about equality and freedom, we argue that feminists should not ignore them, as this would neglect the particularity of secular feminist positions and exclude the experiences and opinions of women with other perspectives.

Several online discussions and articles show that Muslim women decide to follow certain religious dogmas quite consciously, and try to live accordingly. Lale-Zar from Amsterdam, who describes herself as a social worker writes:

"With a namahrem (a man who is not a woman's father, brother, uncle, grandfather, nephew, or any other male she can marry within the rules of Islam), it is not permitted to have physical contact in any way. It is not that I am not giving a hand to a man because I love that so much, it is easier to give a hand than not give it. I am turning myself in all kinds of shapes to not embarrass the opposite sex when not giving hands, from time to time I also do give a hand and this depends on the person and the setting. Of course I am not justifying this. One of the things that makes me sad is that I am getting more understanding from the men whom I don't shake hands with, than from the people of the same sex (women)" (moslima ansaar, 2012, our translation). ${ }^{11}$

Lale-Zar shows that following strict religious rules in a secular society leads to difficult situations. The criticism she receives when she does not shake hands with men makes her in some cases ignore the rules and take the easy way out. It is an active and constant choice to follow these rules, not something that can easily be dismissed as 'passively following orders'.

Another woman emphasised the need for flexibility in following religious rules:

"I have to be honest that I am not faithful to the prayers. Sometimes I do one while riding a bicycle. I know it is not the way it should be done, but I do it anyways. I still believe it is valuable. There are also other rules that are widely accepted, such as that it is not allowed for Muslim women to have a non-Muslim partner. But I do have a non-Muslim partner. I do not take all rules literally in my life and it is not that I am proud of not obeying these rules, it is just that they do not match with my life." (Nieuwe Moskee interview, 2012, our translation)

One can see that living according to the rules of the Qu'ran requires constant negotiation of what one can do in a secular society and where one better let go. The women in our case study of course made different decisions based on their own evaluations. Women in various fora argued that it is often not Islam that oppresses women but Western ideologies such as capitalism and consumerism. They sometimes argued that they experienced more pressure and obligations from the Western societies they live in than from the religion they want to live by. In this perspective, freedom is often regarded as an illusion. ${ }^{12}$

\section{Rethinking emancipation through Muslim women's online activities and representations}

This article has examined how Muslim women in the Netherlands discuss gender relations and emancipation in relation to their faith and religious practices. The women in our sample were clearly engaged with the struggle for emancipation: they presented alternative perspectives on the concept itself, put forth sophisticated arguments to intervene in discourses that were usually only about them, and advanced their own agendas for women's issues, for example by criticizing the idea that women gain from sexual freedom. Some were also opposed to the idea of emancipation as such, choosing instead to live according to the rules of the Qu'ran.

The Internet was especially important in providing women with information about their faith and the role of women in it, as well as spaces where they can meet and discuss issues with like-minded persons. New media give Muslim women in the Netherlands a chance to practice their religion in their own way: to look up and listen to specific prayers when they want to, to share spiritual messages with their friends, and to discuss what these mean in their lives.

We argued that both standpoint theory and the concept of situated knowledges can help us rethink the relationship between religion and feminism. The former provides feminists with arguments to support and incorporate the struggles of (for example) Muslim women; the latter provides an entry for the narration of alternative stories, such as those of women who do not necessarily want freedom, as defined in liberal discourses. This brings us back to Saba Mahmood and Rosi Braidotti, whose interpretations of subjectivity, agency and knowledge claims have given us the tools to rethink the relationship between religion and feminism, and how to include the arguments, experiences and strategies of women who fight alternative struggles for equality as well as those of women who do not necessarily desire freedom. Nevertheless, there remain unanswered questions, such as how open definitions of agency and subjectivity can be before they begin to endanger feminist struggles.

This paper presented four alternative forms of agency that we found among Muslim women living in the Netherlands: 'rethinking emancipation', 'multiple critique', 'fighting sexualisation' and 'living according to strict rules'. Interpretations of feminism and emancipation varied tremendously between the women in our focus groups. Some instantly saw themselves as feminists; others were opposed to using the term to describe themselves. Among the latter, many saw themselves as 'emancipated' - that is, interested in the struggle for equality but not as it is currently interpreted by certain Western feminists. Many of our informants argued that we need different interpretations of feminism; others preferred the more neutral term 'emancipation'. For most of the women in the focus groups, emancipation was about making one's own choices in life and not just about having a career; they explicitly criticised its more individualistic interpretations.

More inclusive and less normative interpretations of subjectivity and agency would allow feminists to be more open to alternative ways of structuring one's life and achieving change. This would also make it possible to start a dialogue about feminism among all women, without first asking minority women to give up their beliefs or religious backgrounds. A radical dismissal of their beliefs and traditions on the basis of certain dominant views would completely erase these women's struggles and power to achieve change. Furthermore, it prevents feminists from actually discussing the issues at stake, rather than constantly emphasising certain principles. We argue that through more flexible interpretations 
of agency, the experiences of more women can form new feminist knowledges.

This would only be possible through an intersectional approach, and the understanding that various axes of difference coincide and influence each other, that gender intersects with religion and religion is 'gendered'. In the group interviews, women underlined both their gender and religion - that they could not and would not choose between the two: they were both women and Muslim, and needed to develop a framework for emancipation accordingly. It follows that any feminist intervention that begins with the idea that women must give up their religious identity in order to be emancipated is highly problematic.

The analysis of new possibilities for agency in the digital sphere - where Muslim women negotiate between emancipation and religion in different and multiple ways - was at the core of our analysis. We have shown how the exploration of new digital environments such as blogs, Muslim websites and social networks offer new insights into how digital faith and the struggle for emancipation connect and intersect in different ways - ways that need to be further explored, especially in light of feminist theory.

\section{Acknowledgements}

We would like to thank the men and women who participated in our interviews/focus groups; Liza Mugge for editing this special issue; our anonymous reviewers for their constructive comments and Takeo David Hymans for copy editing our article.

\section{Endnotes}

${ }^{1}$ http://www.mignetproject.eu/.

${ }^{2}$ Think for instance of Susan Moller Okin (who in 1999 already argued that multiculturalism was bad for women) but also of Ayaan Hirsi Ali in the Netherlands.

${ }^{3}$ Please note that not all secular feminists were/are critical about religion in relation to gender equality, but the feminists who were stating their worries about the influence of Islam on the posiiton of women in the Netherlands, were very explicitly secular.

${ }^{4}$ http://www.nieuwemoskee.nl/2011/11/gelijkwaardigheid-van-manen-vrouw-in-de-islam/

${ }^{5}$ http://www.wijblijvenhier.nl/1938/feminisme-oude-stijlfeminimalisme/

${ }^{6}$ http://www.nieuwemoskee.nl/2010/12/versteende-beelden/

${ }^{7}$ http://www.nieuwemoskee.nl/2010/12/versteende-beelden/.

${ }^{8}$ http://www.wijblijvenhier.nl/1239/gelijkheid-of-gelijkwaardigheid/

${ }^{9}$ http://www.nieuwemoskee.nl/2012/01/een-blote-knie/

${ }^{10}$ http://www.nieuwemoskee.nl/2012/01/een-blote-knie/
${ }^{11}$ http://forum.turksestudent.nl/index.php/topic/44869-kadyn-eli-sykmakharam-my/page_st_15 (accessed 23-02-2012)

12 http://moslima.ansaar.nl/index.php/component/content/article/71verhalen-van-zusters/158-vrijheid-lijkt-mooi-maar-het-is-een-illusie

\section{References}

Ang, Ien (2003). I am a feminist but..."other" women and postnational feminism. In R. Lewis, \& S. Mills (Eds.), Feminist postcolonial theory. A reader (pp. 190-207). New York: Routledge.

Bock, Gisela, \& James, Susan (1992). Introduction: Contextualizing equality and difference. 1992. In Bock, \& James (Eds.), Beyond equality and difference: Citizenship, feminist politics, and female subjectivity (pp. 1-17). London: Routledge.

Bracke, Sarah (2008). Conjugating the modern/religious, conceptualizing female religious agency: Contours of a 'post-secular' conjuncture. Theory, Culture, and Society, 25(6), 51-67.

Braidotti, Rosi (2008). In spite of the times: The postsecular turn in feminism. Theory, Culture, and Society, 25(6), 1-24.

Buikema Rosemarie and Smelik Anneke (red). (1993) Vrouwenstudies in de Cultuurwetenschappen. Muiderberg: Coutinho.

Chanter, Tina (1998). Postmodern subjectivity. In A. M. Jaggar, \& I. M. Young (Eds.), A companion to feminist philosophy (pp. 263-271). Oxford: Blackwell Publishers.

The Combahee River Collective (1977). A black feminist statement. In B. Guy-Sheftall (Ed.), (1995) Words of fire: An anthology of African-American feminist thought (pp. 231-240). New York: New Press.

Cooke, Miriam (2002). Multiple critique: Islamic feminist rhetorical strategies. In L. E. Donaldson, \& K. Pui-lan (Eds.), Postcolonialism, feminism and religious discourse (pp. 142-161). London/New York: Routledge.

Fairclough, Norman (2001). Language and power. London: Longman.

Haraway, Donna (1991). Situated knowledges: The science question in feminism and the privilege of partial perspective. In Haraway D. Simians (Ed.), Cyborgs and women. The reinvention of nature. (pp. 183-203). London: Free Association Books.

Harding, Sandra (1991). Whose science? Whose knowledge? Thinking from women's lives. Ithaca/New York: Cornell University Press.

Korteweg Anna (this issue).

Kozinets, Robert (2010). Netnography. Doing ethnographic research online. London: Sage.

Leavy, Patricia Lina (2007). The practice of feminist oral history and focus groups interviews. In Nagy Hesse-Biber, \& Leavy (Eds.), Feminist research practice: A primer (pp. 149-187). London: Sage.

Mahmood, Saba (2005). Politics of piety. The Islamic revival and the feminist subject. Princeton and Oxford: Princeton University Press.

Midden, Eva (2012). Feminism and cultural and religious diversity in Opzij. An analysis of the Dutch feminist magazine. European Journal of Women's Studies, 19(2).

Midden, Eva (in press). Agency through faith. In M. Cornis Pope (Ed.), (Re-) writing religious and gender identities in the Netherlands. Literature and multimedia in late 20th and 21st century Europe. Amsterdam: John Benjamin's Press (in press).

van der Haar, Marleen (2013). 'Coming down from their thrones'? Framing migrant men in Dutch politics. Women's Studies International Forum, 41, 215-222 (this issue).

Wilkinson, Sue. (2004). Focus groups: A feminist method. In Hesse-Biber, \& Yaiser (Eds.), Feminist perspectives on social research (pp. 271-296). Oxford: Oxford University Press 2004. 